\title{
Annexin A5 as a marker for hepatocellular carcinoma in cirrhotic hepatitis $C$ virus patients
}

\author{
Waleed Mohamed Serag ${ }^{1^{*}}$ (D) and Basem Eysa Elsayed ${ }^{2}$ (D)
}

\begin{abstract}
Background: The tumorigenesis and development in a variety of cancers is reportedly encouraged via Annexin A5. The levels of Annexin A5 were tested in patients with or without HCC who were affected by liver cirrhosis. The objective of our study was to detect Annexin A5 levels in such patients in order to assess their function as an HCC marker. The longitudinal study comprised 91 cirrhotic HCV patients with and without HCC, and 20 healthy volunteers in the control group approved by the National Hepatology and Tropical Medicine Research Institute (NHTMRI) between March 2017 and August 2018.The serum levels Annexin A5 were found in all groups with ELISA. ANOVA, Mann-Whitney, and $x^{2}$ tests had been applied.
\end{abstract}

Results: High scales of Annexin A5 (3.89 + 0.85) were recorded for cirrhosis with HCC, either than cirrhotic patients without HCC $(3.06 \pm 0.88)(P=0.041)$, and either than the control group $(0.54 \pm 0.11)(P<0.001)$.

Conclusion: In HCV cirrhotic patients with and without HCC, AnxA5 can be used as HCC marker.

Keywords: AnxA5 level, HCV, HCC, Cirrhosis

\section{Background}

One of the world's most common cancers is hepatocellular carcinomas (HCC). Epidemiologic studies have shown that $\mathrm{HCC}$ is the fifth and seventh most diagnosed cancer among men and women and the world's second and sixth cancer cause for death [1]. The main cause of cancer-related death is hepatocellular carcinoma (HCC), which causes about 800,000 deaths worldwide in 2018 [2]. There is a definite need for non-invasive quantifiable biomarkers to classify the early stages of HCC in order to minimize HCC morbidity and mortality [3]. Annexins are water soluble proteins, usually present in many animals, tissues, and cells. These proteins bind calcium and phospholipids and form ion voltage channels which are calcium-dependent. They are inscribed in cell signals, apoptosis, and control of various inflammatory elements, such as cytokines. Annexin A5 (Annex A5) is a member

\footnotetext{
* Correspondence: waleed.ibrahim@suezuniv.edu.eg

${ }^{1}$ Faculty of Science, Suez University, Suez, Egypt

Full list of author information is available at the end of the article
}

of the $36 \mathrm{kDa}$ molecular weight annexin family which is based on the $\mathrm{Ca} 2+$ membrane binding [4]. Inhibition of pro-Inflammatory actions during apoptosis, Annexin-A5 appears to be of significance. Annexin-A5 was suggested to act as an active and selective anti-inflammatory agent to minimize inflammation during apoptosis [5]. The circulating AnxA5 can be emitted from wounded myocardial tissue, vascular endothelial and smooth muscular cells, liver secretary cells, and spleen; once it is in the plasma, it binds to blood cells (platelets and erythrocytes) or to endothelial cells [6] or also can be released from apoptotic particles derived from circulating blood cells, and the level of which has been shown to reflect severity of cell damage [7]. The levels of annexin gene expression inside human organs vary from universal to selective (for example A1, A2, A4, A5, A6, A7, and A11 annexes), including neutrophil annexin A3, placental and skin annexin A8, tongue A9, stomach annexin A10, and small intestine annexin A13 [8]. It is well known that ANXA5 can be liberated from damaged or dying 
Table 1 Demographic, clinical, and biochemical properties of all classes

\begin{tabular}{|c|c|c|c|c|c|}
\hline Variables & $\begin{array}{l}\text { Cirrhosis with HCC group } \\
(n=44)\end{array}$ & $\begin{array}{l}\text { Cirrhosis without HCC group } \\
(n=47)\end{array}$ & P1value & $\begin{array}{l}\text { Control group } \\
(n=20)\end{array}$ & $P$ value \\
\hline Age (years) & $57.7 \pm 5.75$ & $56.8 \pm 6.89$ & 0.968 (NS) & $54.5(50.5-60.5)$ & 0.337 (NS) \\
\hline $\operatorname{Sex}(M / F)$ & $23 / 21$ & $27 / 20$ & 0.751 (NS) & $10 / 10$ & 0.587 (NS) \\
\hline MELD & $16.1 \pm 4.16$ & $15.1 \pm 4.57$ & 0.568 (NS) & - & - \\
\hline Child-Pugh class (A/B/C) & $12 / 20 / 12$ & $14 / 18 / 14$ & 0.733 (NS) & - & - \\
\hline $\operatorname{ALT}(\mathrm{U} / \mathrm{L})$ & $51 \pm 17.65$ & $53.3 \pm 15.94$ & 0.761 (NS) & $11.9 \pm 3.47$ & $<0.001^{*}(\mathrm{HS})$ \\
\hline $\mathrm{AST}(\mathrm{U} / \mathrm{L})$ & $69 \pm 23.39$ & $68.2 \pm 19.51$ & 0.944 (NS) & $15.4 \pm 4.83$ & $<0.001^{*}(\mathrm{HS})$ \\
\hline ALKP (U/L) & $107.60 \pm 37.05$ & $114.40 \pm 41.84$ & 0.068 (NS) & $48.6 \pm 10.49$ & $<0.001^{*}(\mathrm{HS})$ \\
\hline GGT (mg/dl) & $51.09 \pm 37.75$ & $48.94 \pm 26.37$ & 0.818 (NS) & $14.6 \pm 4.57$ & $<0.001^{*}(\mathrm{HS})$ \\
\hline INR & $1.5 \pm 0.47$ & $1.59 \pm 0.51$ & 0.542 (NS) & $1.005 \pm 0.49$ & $<0.001^{*}(\mathrm{HS})$ \\
\hline PT(s) & $17.51 \pm 4.21$ & $18.62 \pm 4.64$ & 0.533 (NS) & $13.07 \pm 0.18$ & $<0.001^{*}(\mathrm{HS})$ \\
\hline Total bilirubin (mg/dl) & $2.55 \pm 1.61$ & $2.59 \pm 2.01$ & 0.579 (NS) & $0.49 \pm 0.25$ & $<0.001^{*}(\mathrm{HS})$ \\
\hline Albumin (g/dl) & $2.97 \pm 0.72$ & $2.54 \pm 0.79$ & 0.098 (NS) & $4.43 \pm 0.59$ & $<0.001^{*}(\mathrm{HS})$ \\
\hline Platelet count $\left(\times 10^{3} / \mathrm{cm}^{2}\right)$ & $113.04 \pm 24.94$ & $111.32 \pm 17.63$ & 0.935 (NS) & $297.7 \pm 17.87$ & $<0.001^{*}(\mathrm{HS})$ \\
\hline APRI score & $1.88 \pm 0.58$ & $1.93 \pm 0.61$ & 0.794 (NS) & $0.11 \pm 0.03$ & $<0.001^{*}(\mathrm{HS})$ \\
\hline FIB-4 score & $5.47 \pm 1.04$ & $5.32 \pm 1.37$ & 0.709 (NS) & $0.57 \pm 0.14$ & $<0.001^{*}(\mathrm{HS})$ \\
\hline Annexin A5 (ng/ml) & $3.89 \pm 0.85$ & $3.06 \pm 0.88$ & $0.041(S)$ & $0.54 \pm 0.11$ & $<0.001^{*}(\mathrm{HS})$ \\
\hline $\operatorname{AFP}(\mathrm{ng} / \mathrm{ml})$ & $270 \pm 35$ & $98 \pm 20$ & $<0.001^{*}(\mathrm{HS})$ & $5.3 \pm 2.9$ & $<0.001^{*}(\mathrm{HS})$ \\
\hline
\end{tabular}

cells not explicitly [9]. In understanding how the presence of $\mathrm{HCC}$ can affect the weather equilibrium, it is important to consider the sense in which HCC is present, which is basically often a complication of cirrhosis to the liver [10], with the prevalence of cirrhosis among patients with HCC estimated of 85-95 [11]. By superimposed conditions, like HCC, the rebalanced and unstable hemostasis of hepatic cirrhosis can easily be tipped to thrombotic complications. In non-cirrhotic liver, HCC can develop, according to Kulik L.et al.; in a most recent analysis, the occurrence of $\mathrm{HCC}$ without prior cirrhosis is unusual and specifically about $15 \%$ of HBV-related cases [12]. The objective of our study was to detect Annexin A5 levels in such patients in order to assess their function as an $\mathrm{HCC}$ marker.

\section{Methods}

The longitudinal study comprised 44 patients with HCC cirrhosis ( 23 were male and 21 were female), 47 patients without HCC cirrhosis (27 were male and 20 are female), and 20 control healthy (10 were male and 10 were female) without evidence for the diseases of the liver approved by the National Hepatology and Tropical Medicine Research Institute (NHTMRI) between March 2017 and August 2018. The formal consent was given to all studied citizens. The NHTMRI Ethics Committee has approved this analysis under serial No. 15/2016. The study has been organized in accordance with the Declaration of Research on Human Subject in Helsinki for human subject's research. Both of the patients were diagnosed with hepatic biopsy histology, simple lab changes, and ultrasound from Doppler. The magnitude of liver disease was calculated in accordance with the MELD score and the Child-Pugh classification. Cirrhosis with and without HCC impacted hepatitis $\mathrm{C}$ and laboratory and imagery studies based on guidelines for AASLD practice have been clinically conformed. The exclusion criteria were patients of different malignancies that could raise the level of Annexin A5 such as colorectal cancer and pancreatic cancer. The amount of the serum anxA5 was calculated on Stat Fax 4700 Microstrip Reader1 ELISA Microstrip Reader by means of a commercial enzyme immunoassay (SinoGeneClon Biotech Co., Ltd).

\section{Statistical analysis}

All statistical analyses were evaluated in SPSS Version 19. Quantitative variables are listed as mean $+\mathrm{SD}$ or median, while qualitative variables are listed as frequencies. In order to differentiate the three classes, one way

Table 2 Annexin V level in cirrhotic HCV patients with HCC group

\begin{tabular}{lllllll}
\hline & Cut off & Sens. (\%) & Spec. (\%) & +PV (\%) & -PV (\%) & AUC \\
\hline Serum Annexin A5 level & $>3.2(\mathrm{ng} / \mathrm{ml})$ & 80 & 55.8 & 43.8 & 93.5 & 0.566 \\
\hline
\end{tabular}


Table 3 Annexin V level in cirrhotic HCV patients without HCC group

\begin{tabular}{lllllll}
\hline & Cut off & Sens. (\%) & Spec. (\%) & +PV (\%) & -PV (\%) & AUC \\
\hline Serum Annexin A5 level & $\leq 3.1(\mathrm{ng} / \mathrm{ml})$ & 50 & 53.66 & 13.6 & 88 & 0.571 \\
\hline
\end{tabular}

analysis of variance (ANOVA) was used. A nonparametrical analysis was performed by Mann-Whitney, and a parametric student evaluation was performed when a categorical test of $\chi^{2}$ had been applied. Statistically important was a $P$ value below 0.05 .

\section{Results}

Ninety-one cirrhotic patients, 44 HCC, and 47 HCC-free were recruited. Twenty healthy people were also hired (control group). Table 1 displays demographic, clinical, and biochemical properties of all classes.

No statistically significant differences in sex, age, albumin, ALKB, ALT, AST, GGT, T-bilirubin, PT, INR, platelet count, APRI score, and FIB-4 score were discovered between cirrhotic group with $\mathrm{HCC}$ and cirrhotic group without HCC (Table 1). There were statistically important variations between the two groups regarding AFP $(P<0.001)$ (Table 1$)$. There were statistically relevant differences in Annexin A5 values $(P=0.041)$ between the two groups (Table 1). ROC curve reveals that in the cirrhotic HCC group, Annexin A5 has AUC 0.566 and in the cirrhotic group without HCC has AUC 0.571 (Tables 2 and 3; Figs. 1 and 2).

\section{Discussion}

Annexin A5 has been shown to facilitate tumorigenesis and cancers such as hepatocarcinoma, breast, colorectal, pancreas, bladder, and prostate cancer $[13,14]$. In most different types of tumors, including liver cancer, ANXA5 exhibits tumor promoter activity. Two-dimension gel electrophoresis was used by Guo et al. to analyze protein expression in five pairs of tumor and tumor thrombal matched samples, which showed an upregulation of ANXA5 in tumor thrombus samples [15]. Sun and others reported that ANXA5 expression was positive for liver cancer progression and metastasis and that ANXA5 promoted cancer through the integrin and mitogen-activated protein kinase-extracellular signal-regulated kinase pathways [16]. Anxa5 could be a predictive biomarker for tumor development, metastasis, and invasion and be of diagnostic, prognostic, and therapeutic significance in cancer [14]. In addition, Sun and Zhuang et al. showed that HCC expression in ANXA5 was higher than normal liver tissue [16, 17]. The findings of the present study indicate, as compared the cirrhotic patients with and without $\mathrm{HCC}$, that the expression of ANXA5 was increased

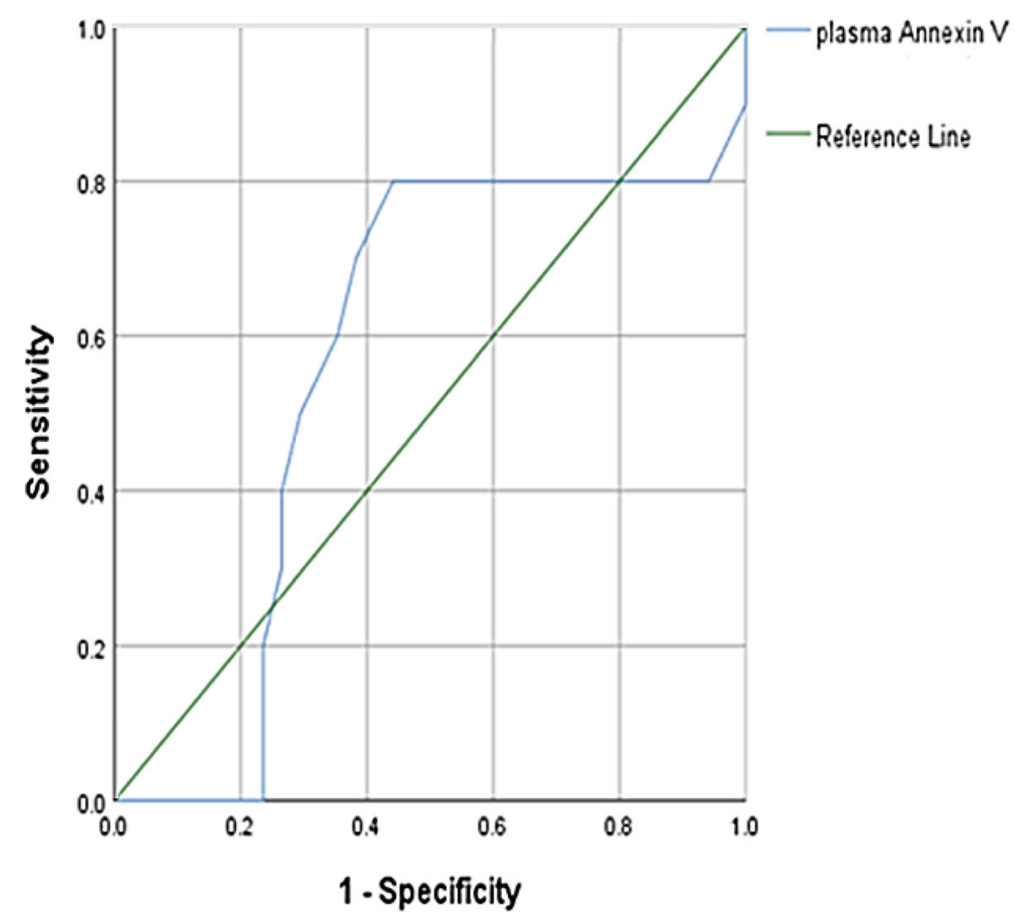

Fig. 1 Serum Annexin A5 ROC curve in HCC group cirrhotic patients 


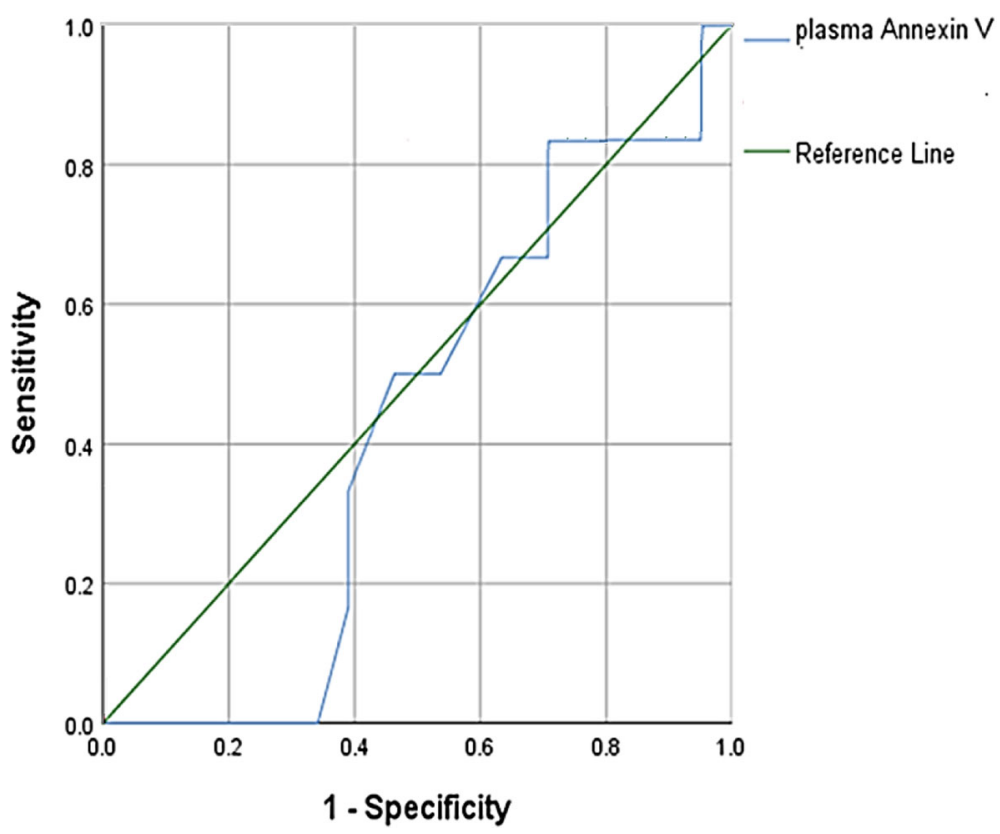

Fig. 2 Serum Annexin A5 ROC curve in cirrhotic patients without HCC

in $\mathrm{HCC}$ cirrhotic $\mathrm{HCV}$ patients. In addition, the pronounced role of ANXA5 in liver cancer has not been documented to the best of our knowledge. In another review, high ANXA5 expression has been shown to be correlated significantly with poor overall survival [17]. AnxA5 has proved to participate in a wide range of intra- and extracellular processes including blood clotting, signal translation, antiinflammatory processes, membrane trafficking, and ion channel activity, but it has not yet established the exact biological function of anxA5. However, it is assumed that the biological functions of anxA5 rely primarily on the interaction between them and lipids of the membranes [18], and at least two crucial physiological mechanisms are regulated: the cascade of coagulation, which is known to involve anticoagulant activity, and apoptosis [19]. Various research models have used annexin A5 as a probe to measure apoptosis in vitro and in vivo. A noninvasive imaging protocol using annexin A5 has been developed and applied successfully to measure programmed cell death in patients [20]. In addition, our study match to previous results showing that HCC hepatitis $C$ patients have greater levels of microparticles than HCC-free hepatitis $\mathrm{C}$ patients, and these levels of microparticles dynamically alter after surgery [21]. In contrast to healthy controls, the explanation of the presence of microparticles in cirrhotic liver is possibly due to systemic inflammation and liver cell damage [22], asserting microparticulate roles that are included in hepatic fibrosty process in mediation of anti-inflammatory reactions, endothelial damage, and coagulation activation.

\section{Conclusion}

In $\mathrm{HCC}$ prediction in cirrhotic $\mathrm{HCV}$ patients, serum Annexin A5 values were found to be a forecasting factor. Larger scale tests are important to promote the use of an inexpensive and easily accessible Annexin A5 biomarker as HCC marker in HCV cirrhotic patients.

\section{Limitation of study}

In our analysis, the sample size of the control group compared to the disease group is relatively small. Finally, it would have been more fitting if the control group number was at least equal to the diseased group.

\section{Recommendation}

Wide sample sizes are suggested to validate this result.

Abbreviations

AnxA5: Annexin A5; HCV: Hepatitis C virus; HCC: Hepatocellular carcinoma

\section{Acknowledgements}

Great confession of collaboration for all NHTMRI doctors.

\section{Authors' contributions}

WS was responsible for the practical section, analysis of data, and manuscript preparation. BE was responsible for the selection and classification of the samples and the manuscript revision. The final manuscript was read and accepted by all contributors.

\section{Funding}

No particular support from publicly supported, financially or non-profit organizations has been granted in this research. 


\section{Availability of data and materials}

The published article [and its supplementary information files] contains all the data produced or analyzed during this research.

\section{Declarations}

Ethics approval and consent to participate

Informative approval from all study participants, with the number 15/2016 of the National Institute of Hepatology and Tropical Medicine Research, was obtained written and validated by the Ethical Committee.

\section{Consent for publication}

Not applicable

\section{Competing interests}

The authors note that the work reported in this paper was not known for its conflict of financial interests or personal relationships.

\section{Author details}

${ }^{1}$ Faculty of Science, Suez University, Suez, Egypt. ${ }^{2}$ National Hepatology and

Tropical Medicine Research Institute, Cairo, Egypt.

Received: 17 February 2021 Accepted: 28 April 2021

Published online: 07 May 2021

\section{References}

1. Jemal A, Bray F, Center MM, Ferlay J, Ward E et al (2011) Global cancer statistics. CA: Cancer J. Clin 61:69-90. https://doi.org/10.3322/caac.201072

2. Bray F, Ferlay J, Soerjomataram I, Siegel RL, Torre LA, Jemal A (2018) Global cancer statistics 2018: GLOBOCAN estimates of incidence and mortality worldwide for 36 cancers in 185 countries. CA: Cancer J. Clin 68(394):424424. https://doi.org/10.3322/caac.21492

3. Marrero JA, Kulik LM, Sirlin CB, Zhu AX, Finn RS, Abecassis MM, Roberts LR, Heimbach JK (2018) Diagnosis, staging, and management of hepatocellular carcinoma: 2018 practice guidance by the American Association for the Study of Liver Diseases. Hepatology 68:723-750. https://doi.org/10.1002/ hep.299132

4. Bouter A, Carmeille R, Gounou C, Bouvet F, Degrelle S et al (2015) AnnexinA5 and cell membrane repair. Placenta 36:S43-SS9. https://doi.org/10.1016/j. placenta.2015.01.193

5. Francesconi L, Ceresér K, Mascarenhas R, Stertz L, Gama C et al (2011) Increased annexin- $V$ and decreased TNF-alpha serum levels in chronicmedicated patients with schizophrenia. Neurosci. Lett. 502:143-146. https:// doi.org/10.1016/j.neulet.2011.06.0423

6. Roldán V, Marn F, Pineda J, Marco P, Corral J, Climent V, García A, Martínez $J G$, Sogorb F (2002) nexina $V$ en pacientes supervivientes de un infarto de miocardio prematuro. Rev Esp Cardiol. 55:1230-1234. https://doi.org/10.101 6/S0300-8932(02)76794-812

7. Lai C, PC C, Wong S, Kw C, Yf C. (2012). Circulating Annexin A5 levels after atrial switch for transposition of the great arteries.

8. Mirsaeidi M, Gidfar S, Vu A, Schraufnagel D (2016) Annexins family: insights into their functions and potential role in pathogenesis of sarcoidosis. $J$ Transl Med 14:1-9. https://doi.org/10.1186/s12967-016-0843-71

9. Kaneko N, Matsuda R, Hosoda S, Kajita T, Ohta Y (1996) Measurement of plasma annexin $\mathrm{V}$ by ELISA in the early detection of acute myocardial infarction. Clin. Chim. Acta 251:65-80. https://doi.org/10.1016/0009-8981 (96)06294-81

10. Velázquez RF, Rodríguez M, Navascués CA, Linares A, Pérez R et al (2003) Prospective analysis of risk factors for hepatocellular carcinoma in patients with liver cirrhosis. Hepatology 37:520-527. https://doi.org/10.1053/jhep.2 003.500933

11. Heimbach JK, Kulik LM, Finn RS, Sirlin CB, Abecassis MM, Roberts LR, Zhu AX Murad MH, Marrero JA (2018) (2018). AASLD guidelines for the treatment of hepatocellular carcinoma. Hepatology 67:358-380. https://doi.org/10.1002/ hep.290861

12. Kulik L, El-Serag HB (2019) Epidemiology and management of hepatocellular carcinoma. Gastroenterology 156:477-91. e1.https://doi.org/1 0.1053/j.gastro.2018.08.065. 156(2):477-491.e1

13. Wang J, Zhang Y, Liu X, Ma J, Liu P et al (2014) Annexin A5 inhibits diffuse large B-cell lymphoma cell invasion and chemoresistance through phosphatidylinositol 3-kinase signaling. Oncol. Rep. 32:2557-2563. https:// doi.org/10.3892/or.2014.35476

14. Peng B, Guo C, Guan H, Liu S, Sun M-Z (2014) Annexin A5 as a potential marker in tumors. Clin. Chim. Acta 427:42-48 https://doi.org/10.1016/j.cca.2 013.09 .048

15. Guo W-X, Man X-B, Yuan H-X, Shi J, Xue J, Wu MC, Cheng SQ (2007). Proteomic analysis on portal vein tumor thrombus-associated proteins for hepatocellular carcinoma. Zhonghua yi xue za zhi 87:2094-2097. PMID: 17988525, 30

16. Sun X, Liu S, Wang J, Wei B, Guo C, Chen C, Sun MZ et al (2018) Annexin A5 regulates hepatocarcinoma malignancy via CRKI/II-DOCK180-RAC1 integrin and MEK-ERK pathways. Cell Death Dis. 9:1-16. https://doi.org/10.1038/ s41419-018-0685-86

17. Zhuang C, Wang P, Sun T, Zheng L, Ming L (2019) Expression levels and prognostic values of annexins in liver cancer. Oncol. Lett. 18:6657-6669 https://doi.org/10.3892/ol.2019.11025

18. Ravassa S, Bennaghmouch A, Kenis H, Lindhout T, Hackeng T, Narula J, Hofstra L, Reutelingsperger C (2005) Annexin A5 down-regulates surface expression of tissue factor a novel mechanism of regulating the membrane receptor repertoir. J. Biol. Chem. 280:6028-6035. https://doi.org/10.1074/jbc. M4117102007

19. Baleva M, Hristova M, Nikolov K (2010) Diagnostic significance of antiannexin-A5 antibody determination. Open Med. 5:6-11. https://doi.org/1 0.2478/s11536-009-0132-41

20. Corsten MF, Hofstra L, Narula J, Reutelingsperger CP (2006) Counting heads in the war against cancer: defining the role of annexin A5 imaging in cancer treatment and surveillance. Cancer Res 66(3):1255-1260. https://doi. org/10.1158/0008-5472.CAN-05-3000

21. Brodsky SV, Facciuto ME, Heydt D, Chen J, Islam HK, et al.(2008). Dynamics of circulating microparticles in liver transplant patients. J Gastrointestin Liver Dis 17:261-268. PMID: 18836617

22. Rautou PE, Bresson J, Sainte-Marie Y, Vion AC, Paradis V et al (2012) Abnormal plasma microparticles impair vasoconstrictor responses in patients with cirrhosis. Gastroenterology 143:166-76.e6. https://doi.org/10.1 053/j.gastro.2012.03.040

\section{Publisher's Note}

Springer Nature remains neutral with regard to jurisdictional claims in published maps and institutional affiliations.

\section{Submit your manuscript to a SpringerOpen ${ }^{\circ}$ journal and benefit from:}

- Convenient online submission

- Rigorous peer review

- Open access: articles freely available online

High visibility within the field

- Retaining the copyright to your article

Submit your next manuscript at $\boldsymbol{\nabla}$ springeropen.com 